\section{Estudo \\ CoDebate}

em Testão

Plamejamento
Revista Estudo \& Debate, Lajeado, v. 26, n. 4, 2019. ISSN 1983-036X DOI: http://dx.doi.org/10.22410/issn.1983-036X.v26i4a2019.2178

\title{
INFLUÊNCIA DOS ACIDENTES DE TRÂNSITOS EM RODOVIAS FEDERAIS SOBRE OS CUSTOS DO SISTEMA ÚNICO DE SAÚDE, NO PERÍODO 2002 A 2012
}

\author{
Mayara Xavier Moraes ${ }^{1}$, Graciela Aparecida Profeta ${ }^{2}$, Vladimir Faria dos Santos ${ }^{3}$, \\ Vanuza da Silva Pererira $\mathrm{Ney}^{4}$
}

\begin{abstract}
Resumo: O número de acidentes de trânsito no Brasil é alarmante, o que faz com que seja necessária uma atenção sobre este fato. Logo, o presente artigo objetivo identificar e mensurar os impactos dos determinantes dos custos que o SUS tem com os acidentes de trânsito que ocorrem em rodovias federais brasileiras. A fundamentação teórica foi construída com base nas discussóes sobre economia e saúde e como estas poderiam se relacionar com os acidentes de trânsito. Em termos metodológicos, utilizou-se o método econométrico de dados em painel, que foi aplicado aos dados sobre as seis rodovias federais concedidas na primeira etapa do Programa de Exploração de Rodovias (PER) do Brasil, entre os anos de 2002 a 2012. A partir da regressáo, os resultados mostraram que as variáveis Colisão Traseira e Quilometragem (trecho concedido) foram as mais importantes para explicar os custos do SUS.
\end{abstract}

Palavras-chave: Economia e saúde, custo do SUS, dados em painel.

\section{INFLUENCE OF TRAFFIC ACCIDENTS ON FEDERAL HIGHWAYS ON THE COSTS OF THE UNIFIED HEALTH SYSTEM, FROM 2002 TO 2012}

\begin{abstract}
The number of traffic accidents in Brazil is alarming, which requires attention to this fact. Therefore, this article aims to identify and measure the impacts of the cost determinants that SUS has on traffic accidents that occur on Brazilian federal highways. The theoretical foundation was built based on discussions about economics and health and how they could relate to traffic accidents. In methodological terms, we used the
\end{abstract}

1 Graduada em Ciências Econômicas (UFF). Graduanda em Administração de Empresas (UFRRJ).

2 Professora Adjunto III do Curso de Ciências Econômicas (UFF). Mestre e Doutora em Economia Aplicada (UFV). Graduada em Gestão do Agronegócio (UFV).

3 Professor Adjunto IV do Curso de Ciências Econômicas (UFF). Mestre e Doutor em Economia Aplicada (UFV). Graduado em Ciências Econômicas (UFV).

4 Professora Associada I do Curso de Ciências econômicas (UFF). Mestre em Economia (UFES). Doutora em produçáo vegetal (UENF). Graduada em Ciências econômicas (EFES). 
panel data econometric method, which was applied to data on the six federal highways granted in the first stage of the Brazilian Highway Exploration Program (PER), from 2002 to 2012. The From regression, the results showed that the variables Rear Collision and Mileage (stretch granted) were the most important to explain the costs of SUS.

Keywords: Economy and health, SUS cost, panel data.

\section{Introduçáo}

Os acidentes no trânsito, de acordo com estudos realizados pela Organização Mundial de Saúde - OMS, considerando-se informaçóes do ano de 2010, mataram cerca de 1,24 milhóes de pessoas por ano, sendo que $90 \%$ destes ocorreram em países de média e baixa renda. Estes acidentes são a principal causa de morte de jovens entre 15 e 29 anos em todo o mundo. Além disso, se nada for feito, de acordo com o estudo denominado "Mapa da violência em 2013", estima-se que em todo o mundo poderá ocorrer 1,9 milhão de mortes no trânsito até 2020 e 2,4 milhões até 2030 (MAPA DA VIOLÊNCIA, 2013).

Segundo informaçóes da Organização Pan-Americana da Saúde (OPAS) de 2019, aproximadamente 1,35 milhão de pessoas morrem a cada ano em decorrência de acidentes no trânsito; sendo que estes custam à maioria dos países, 3\% de seu Produto Interno Bruto (PIB). Ainda conforme OPAS (2019), 93\% das mortes no trânsito ocorrem em países de baixa e média renda, embora estes concentrem aproximadamente $60 \%$ dos veículos do mundo.

Conforme relatório do World Health Organization- WHO, de 2018, considerando dados de 2000 a 2016, observou-se que dos países que pertencem ao BRICS (Brasil, China, Índia, Rússia e África do Sul), os que apresentaram maior percentual de mortes em relação à população de 2016, foram nesta ordem: África do Sul $(25$ mortes a cada $100 \mathrm{mil}$ habitantes); Brasil (18 mortes a cada 100 mil habitantes) Rússia (14 mortes a cada $100 \mathrm{mil}$ habitantes), Índia (11 mortes a cada 100 mil habitantes) e China (quatro mortes a cada 100 mil habitantes). Quando se somam ao BRICS os países da América do Sul, o Brasil passa a ocupar, levando em conta 13 países, a $3^{\text {a }}$ posição, ficando atrás somente da Venezuela (22 mortes a cada 100 mil habitantes) e da África do Sul (25 mortes a cada 100 mil habitantes). Logo, esses dados demonstram o quanto de fato é importante analisar os custos dessas mortes para o país e que as medidas tomadas até entáo, tem surtido pouco efeito em termos de melhoria na segurança do transito.

Já, conforme estudo realizado pelo Instituto de Pesquisa Econômica Aplicada-IPEA (2016), intitulado "Mortes por Acidentes de Transporte Terrestre no Brasil: Análise dos Sistemas de Informaçáo do Ministério da Saúde", no ano de 2013, ocorreram 43 mil mortes em acidentes de trânsito no Brasil, sendo 21 mortes a cada 100.000 habitantes. No mesmo ano, houve aproximadamente 170 mil internaçôes financiadas pelo Sistema Único de Saúde (SUS) devido aos acidentes de trânsito, e em 2014 esse montante foi para 180 mil internaçōes. Vale ressaltar que em 2013, 4,62\% das vítimas que estavam internadas vieram a óbito, já em 2014 essa porcentagem foi de 3,06\% (IPEA, 2016). Quanto aos gastos com internaçôes por conta dos acidentes de trânsito no Brasil, segundo a pesquisa do IPEA (2016), observou-se que, de 2010 a 2014, os gastos somaram mais $\mathrm{R} \$ 250$ milhóes por ano, que correspondem a mais de $\mathrm{R} \$ 1$ bilhão no período mencionado. 
Destaca-se que os dados alarmantes sobre os acidentes de trânsito podem ser fruto do sistema de transporte brasileiro que é dependente da malha rodoviária. No caso do Brasil, de acordo com a $19^{a}$ edição do relatório gerencial de pesquisa realizado pela Confederação Nacional de Transporte - CNT, no ano de 2015, este teve grande importância na movimentaçáo de pessoas e bens, haja vista que esse sistema é responsável por $61,1 \%$ da matriz de transporte de cargas no Brasil (CNT, 2016).

Agora, quanto à quantidade de veículos automotores no Brasil, um estudo realizado pelo Observatório das Metrópoles do Instituto Nacional de Ciência e Tecnologia (INCT) tratou da análise da evolução da frota de automóveis e motos no Brasil entre 2001-2012. O estudo mostrou que a frota de veículos teve um crescimento de $138,6 \%$, passando de 34,9 milhōes para 76,1 milhōes (INCT, 2013).

Segundo o IPEA (2015), 32,6\% dos acidentes, em geral, estão relacionados à falta de atenção por parte dos motoristas, sendo que desse montante, $20,3 \%$ referem-se aos acidentes com mortes nas rodovias federais registrados em 2014. Com relação a colisão frontal e atropelamentos, por exemplo, apresentavam baixa ocorrência, sendo $6,5 \%$ do total dos acidentes. Mas, por outro lado, responderam por quase metade das mortes nas rodovias federais. Além disso, também conforme o IPEA (2015), acidentes em função da ingestão de álcool correspondiam a $6,5 \%$ do total, e o desrespeito às regras de trânsito foi a causa mais comum de acidentes com fatalidade, o que demonstra a necessidade de se realizar campanhas educativas e permanentes sobre tal questâo.

A partir desses dados, sabe-se que os acidentes de trânsito causam muitos impactos para a sociedade, uma vez que as vítimas e os familiares envolvidos sofrem danos emocionais, psicológicos e monetários. Ainda que uma vida perdida não possa ser quantificada, conforme evidencia o estudo do IPEA (2016), é possível observar que no Brasil gastam-se por ano cerca de $\mathrm{R} \$ 50$ bilhóes com os acidentes de trânsito, tendo como destaque a perda da capacidade de produção das vítimas e os gastos com atendimento hospitalar. Vale destacar que dos 170 mil acidentes de trânsito nas rodovias federais brasileiras, no ano de 2014, estes acarretaram em um custo de $\mathrm{R} \$ 12,3$ bilhóes para a sociedade, sendo $64,7 \%$ desses custos ligados às vítimas dos acidentes, como os cuidados com a saúde e a perda da capacidade produtiva por conta das lesôes ou morte. Já 34,7\% desses custos estavam ligados diretamente ao veículo, como danos materiais e perda de cargas (IPEA, 2016).

Portanto, diante dos dados apresentados, cabe o seguinte questionamento: quais foram os determinantes dos gastos que o SUS teve com os acidentes de trânsito no Brasil, no período de 2002 a 2012?

Esta pesquisa busca suprir uma lacuna no campo da Economia da Saúde, que ainda se encontra em um estágio embrionário, mesmo que a discussáo quanto à segurança no trânsito encontra-se na agenda política internacional há mais de 40 anos (ORGANIZAÇÃO DAS NAÇÓES UNIDAS- BRASIL- ONUBR, 2015).

A escolha do período de análise justificou-se pela disponibilidade de uma base de dados consolidada, que contempla as principais rodovias concedidas à iniciativa privada no Brasil, na primeira etapa do programa de exploração de rodovias (PER). A razão por considerar apenas as seis rodovias federais cedidas, a saber: NOVADUTRA (Rio de Janeiro 
- São Paulo), PONTE (Rio- Niterói), CONCER (Rio de Janeiro - Juiz de Fora), CRT (Rio de Janeiro- Teresópolis - Além Paraíba), CONCEPA (Osório-Porto Alegre), ECOSU, está no fato de serem estas as mais relevantes em termos de movimentação de cargas e pessoas e da extensão dos trechos concedidos.

Assim, o objetivo geral desta pesquisa foi mensurar e analisar os impactos dos determinantes nos custos econômicos dos acidentes de trânsito em rodovias federais no Brasil, no período de 2002 a 2012.

\section{Referencial teórico}

Nesta seção abordaram-se alguns autores que tratam da Economia da Saúde com o intuito de sustentar as reflexôes realizadas a partir das análises empíricas. Ademais, apresentase também uma discussão em relação aos determinantes dos custos de acidentes no Brasil, que serviu como base para elaborar o modelo econométrico para mensurar os impactos desses determinantes sobre os custos de acidentes no Brasil.

\subsection{Alguns estudos no ramo da economia da saúde}

De acordo com Nero (2002), os autores que iniciaram pesquisas no campo da Economia da Saúde procuravam tratar sobre as questóes sanitárias amplas, às quais refletiam mais numa preocupação médico-social do que em uma tentativa de formular princípios teóricos exclusivos. Assim, têm-se os trabalhos do René Dubos e Henry Sigerist, cujos estudos tiveram seu início entre os anos de 1946 e 1959.

Em âmbito internacional, o Reino Unido se destaca por meio das contribuiçóes de Brian Abel-Smith, vinculado à Escola de Economia e Ciência Política de Londres. Brian Abel-Smith (1976) em seu último livro, Value for Money in Health Services, ressaltou que em todo o mundo, cada vez se gasta mais em serviços de saúde com uma parcela cada vez maior das despesas a cargo da previdência social ou custeada pelos impostos. Logo, mesmo que o direito a esses serviços nem sempre possa estar em textos de teor constitucional ou normativo, já se observa uma tendência de se admitir que cabe ao Estado garanti-lo a todos (LEITE, 1976).

De acordo com Medici (2017), Kenneth Arrowtambém teve a sua importância no ramo da economia da saúde com o trabalho, Uncertaintyandthewelfareeconomicsof medical care, ao publicado pela American Economic Review em 1963. Nesse artigo, Arrow tratou da economia da assistência médica que é uma parte da economia da saúde, que busca estudar as organizaçôes que administram seguros médicos voltados para os cuidados de saúde da população, visando uma forma de administrar riscos. O que se notou pelo trabalho de Arrow é que devido à disponibilidade do seguro, acaba-se criando um potencial de aumento da demanda para ser assegurado.

Já no cenário nacional, a Criação do Sistema Único de Saúde (SUS) no final da década de 1980, pode ser tratada como uma preocupação ligada ao ramo da economia da saúde. Esse sistema tem como objetivo garantir de forma eficaz o direito ao acesso integral à saúde por parte de toda a população brasileira. Assim, com a criação do SUS, o sistema público incorporou milhóes de brasileiros que antes eram atendidos de forma muito desigual no 
país. Além disso, de acordo com o livro intitulado "Sistema de Saúde no Brasil: organização e financiamento - 2016, o direito à saúde hoje é garantido de uma forma parcial ou total em vários países do mundo e deve ser observado como uma construção de base histórica, que nasceu das condiçóes derivadas do desenvolvimento do modo de produçáo capitalista.

Ressalta-se que existem diversas fontes de financiamento do SUS, tais como: empréstimos do Fundo de Garantia por Tempo de Serviço (FGTS); criação de imposto e contribuição vinculada à saúde (Imposto Provisório sobre Movimentação financeira IPMF-e Contribuição Provisória Sobre Movimentaçâo Financeira-CPMF)'; e, a Emenda Constitucional no 29 que definiu os percentuais mínimos de aplicação em açôes e serviços públicos de saúde e estabeleceu regras para o período de 2000 a 2004 (MELAMED e PIOLA, 2011). Para Marques (2016, p.12) "é na sociedade capitalista que assistimos o aparecimento da garantia de acesso a ações e serviços de saúde de um segmento da população de um país".

Vale destacar que a economia, por sua vez, de forma simplista, pode ser entendida como o estudo de como as pessoas conseguem adquirir alimentos, casa, roupas e outros tipos de bens sendo eles de luxo ou de sobrevivência. Enquanto a economia da saúde é essencialmente uma área de estudo onde se aplica a Ciência Econômica num conjunto específico de fenômenos que são relacionados à saúde (FELICISSIMO, 2000).

Assim, de acordo com Nero (2002), a economia e a saúde estão relacionadas de várias formas, seja no seu estudo e pesquisa sistemática, ou na aplicação dos mecanismos econômicos tanto para as questóes estratégicas, quanto operacionais no setor da saúde. Contudo, os economistas ortodoxos precisam fazer certo esforço para poderem compreender o campo da assistência à saúde, visto que os serviços não são apenas uma forma de organizar e distribuir bens e serviços.

O estudo da função distributiva dos sistemas de saúde tem grande destaque na economia da saúde. A equidade, quando se trata de saúde, é um tema bastante discutido e conota equidade de acesso aos serviços, atingindo desde grupos sociocultural até a equidade de utilização e a equidade de resultados terapêuticos (NERO, 2002).

Vale ressaltar que os acidentes de trânsito implicam em uma significativa despesa médico-hospitalar, que quase sempre, sáo de responsabilidade da gestão da saúde pública. Por isso a sua prevenção é muito importante, tanto no que se refere à redução de gastos diretos imputados ao SUS, como também na reduçáo das despesas indiretas juntamente ao sistema de seguridade social. E, sem pormenorizar a perda de uma vida, tem como objetivo tentar reduzir os custos econômicos, sociais e afetivos das vítimas e seus familiares (MASSAU e ROSA, 2016).

Por fim, destaca-se também que mesmo tendo muitas diferenças na atuação do governo entre os variados países, é incontestável seu papel no setor. Isto porque, a responsabilidade governamental é de suma importância quando se trata do uso racional dos recursos públicos investidos na saúde; ou seja, aplicar recursos de forma a alcançar

5 É importante ressaltar que a CPMF foi extinta em 2007 e, portanto, o SUS não mais possui essa fonte. 
resultados positivos em relação aos indicadores de saúde demonstra maior impacto das políticas e programas públicos (NERO, 2002).

\subsection{Determinantes dos custos dos acidentes de trânsito no Brasil}

$\mathrm{O}$ custo no âmbito econômico tem as suas particularidades. Os economistas tratam os custos de uma forma bem distinta dos contadores, os quais estão mais focados em acompanhar os ativos e passivos, como também retratar o desempenho passado para o uso da sociedade, como acontece nos demonstrativos de resultados. Já os economistas apresentam uma visão mais voltada para o futuro, assim eles se preocupam com a alocação dos recursos escassos; ou seja, eles se preocupam com os custos que poderáo ocorrer no futuro e também com medidas que poderão ser usadas para reduzir tais custos.

Isto posto, conforme Massau e Rosa (2016), os acidentes rodoviários, geralmente, demandam atendimento e tratamentos prolongados e, por isso, implicam diretamente na elevação dos custos do SUS. Ademais, esses acidentes além de causar um elevado custo no âmbito da saúde, ainda causam outros impactos sociais e econômicos, pois um indivíduo envolvido num acidente de trânsito pode desenvolver um quadro de comorbidade, onde a depressão e a ansiedade são as consequências mais frequentes (IPEA, 2006).

Além disso, pode-se dizer que um dos determinantes para aumentar o número de acidentes de trânsito, e, por consequência, elevar os custos desses para o SUS, refere-se aos investimentos em infraestrutura rodoviária. Isto porque, de modo geral, a manutenção das vias é primordial para que se tenham melhorias na sua qualidade, e, assim colaborar para a redução dos custos tangíveis e intangíveis de um acidente (CNT, 2016).

Outro determinante importante que pode apresentar impacto significativo no comportamento dos custos de acidentes de trânsito no Brasil refere-se à expansão da frota de veículos automotores, o que pode agravar a situação dos acidentes de trânsito, ainda mais neste contexto de franca expansão da frota que o país vive (WHO-2018). Ressalta-se que, em relação a essa expansão da frota de veículos automotores, as motocicletas proporcionam, aos seus usuários, baixa proteção em caso de colisão e queda, o que pode acarretar num alto grau de severidade dos acidentes que envolvem esse tipo de veículo, aumentando as estatísticas de mortes e feridos graves (IPEA, 2015).

Cabe salientar também que no período de 2001 a 2014 a frota de automóveis do Brasil teve um aumento de 32,3 milhóes, com isso o país terminou o ano de 2014 com um total superior a 56,9 milhóes de veículos. Neste contexto de expansão da frota, observou-se tendência similar em relação à taxa de motorização, para o mesmo período de 2001 a 2014, que passou de 14,4 automóveis para cada 100 habitantes, para 28,1 (OBSERVATÓRIO DAS METRÓLES, 2015).

Ainda segundo o mesmo estudo realizado pelo Observatório das Metrópoles-INCT, em 2015, em relação ao número de motos, notou-se que este saltou de 4,5 milhóes para 22,8 milhóes entre os anos de 2001 e 2014 no Brasil. As mais de 18,3 milhóes de motos que foram acrescidas à frota nesse período correspondem a uma variação percentual da ordem de 403,7\%. Assim, a taxa de motorizaçáo passou de 2,7 motos para cada 100 habitantes em 
2001 para 11,3 em 2014. Somente no ano de 2014 , houve um aumento de $6,6 \%$, o que representa algo em torno de 1,4 milhão de motos.

Conforme o IPEA (2015), a colisão frontal é o principal tipo de acidente que leva a óbito, sendo que somente no ano de 2014 foi responsável por 33,7\% das mortes; seguida pelos atropelamentos de pessoas, responsável por 14,6\%. Em tempo, destaca-se, ainda de acordo com o IPEA (2015), que em 2014, a cada 100 acidentes, morreram aproximadamente 41 pessoas e 29 foram submetidas a cuidados médicos devido ao atropelamento.

Já em relação à colisão traseira, segundo o IPEA (2015), este tipo de acidente é mais frequente nas rodovias federais, e corresponde a 29,2\% dos acidentes gerais, e 8,4\% no caso de morte, apenas quando se considera dados de 2014. Apesar de ser o tipo mais frequente em relação aos acidentes em geral, em se tratando de acidentes letais, a colisão traseira tem uma porcentagem menor se comparado à colisão frontal (IPEA, 2015).

Ainda de acordo com o estudo realizado pela Organização Mundial de Saúde (OMS) e traduzido no ano de 2012 pela Organização Pan-Americana de Saúde, denominado "Gestão da velocidade: um manual de segurança viária para gestores e profissionais da área”, a maioria dos especialistas, a exemplo pode-se citar: Marín e Queiroz (2000) e Pinsky e Pavarino Filho (2007); que estudam sobre a segurança no trânsito, concordam que a primeira causa do elevado número de mortes nas vias públicas em todo o mundo é o excesso de velocidade. Esse excesso aumenta o risco de uma colisão por várias razóes, e, é, portanto, um grave problema de segurança no trânsito em vários países, acarretando em pelo menos um terço de todas as lesóes causadas pelo trânsito.

Ademais, estudos como os dos fatores intrínsecos e ambientais que afetam o comportamento do condutor em relação ao respeito à velocidade limite em vias urbanas, indicam que a velocidades de apenas $5 \mathrm{~km} / \mathrm{h}$ acima da média- de $60 \mathrm{~km} / \mathrm{h}$ em áreas urbanas, e $10 \mathrm{~km} / \mathrm{h}$ acima da média em áreas rurais, para o caso do Brasil, já são suficientes para dobrar o risco de uma colisão com vítimas fatais. As demonstrações também indicam que o excesso moderado de velocidade -entre $10 \mathrm{~km} / \mathrm{h}$ ou $15 \mathrm{~km} / \mathrm{h}$ acima do limite fixado- colabora amplamente para colisóes graves. Logo, de acordo com a Comissão Europeia, em estudo sobre Mobilidade e Transportes, o excesso de velocidade pode aumentar significativamente o risco de acidentes e tem um papel determinante em, aproximadamente, 30\% dos acidentes mortais (COMISSÃO EUROPÉIA, s.d).

Além do excesso de velocidade, outro fator relevante que pode acarretar no aumento do número de acidentes de trânsito e, consequentemente, nos custos econômicos imputados ao SUS, é a ingestão de bebida alcoólica por parte do motorista. Quando se trata, principalmente dos acidentes letais, somente no ano de 2014, a ingestão de álcool correspondeu a $6,5 \%$ dos acidentes com morte e 4,4\% dos acidentes em geral (IPEA, 2015).

No intuito de confirmar a efetividade da Lei Seca, ao analisar dados da Polícia Rodoviária Federal (PRF), estes apontam que a partir de 2012, após a Lei ter estabelecido tolerância zero e aumentado o valor da multa para quem for pego dirigindo embriagado, é possível observar uma redução no número de acidentes que ocorreram por influência do consumo de bebida alcoólica, uma vez que em 2012, foram registrados cerca de 7.594 acidentes; já no ano de 2013 esse valor foi de 7.526; e, em 2014, 7.391. Além disso, de 
acordo com o Ministério da Saúde, em 2015, notou-se uma redução no número de mortes em acidentes de trânsito, sendo que no ano de 2013 foram registradas 42.266 mortes e em 2014 um total de 40.294, logo se observou uma redução de 5\% neste período (EMPRESA BRASIL DE COMUNICAÇÃO S / A, 2016).

Como foi observado, os custos do SUS podem ser influenciados por diversos fatores. Sendo assim, com o intuito de isolar e quantificar tais fatores sobre o custo econômico do SUS, optou-se por aplicar um modelo econométrico, mais especificamente, o modelo de dados em painel.

\section{Metodologia}

Para alcançar os objetivos definidos neste estudo, utilizou-se o modelo econométrico de dados em painel. Nesta seção foram apresentados os procedimentos necessários para ajustar o modelo teórico ao problema desta pesquisa.

\subsection{Modelo Econométrico de Regressão com Dados em Painel}

Dados em painel é um modelo amplamente utilizado na literatura econométrica, cuja formulação envolve duas dimensões: a temporal e a espacial. Conforme Gujarati (2011), as famílias, as empresas e estados, se relacionam num determinado período de tempo, então, com o modelo de dados em painel é possível acompanhar ao longo do tempo o movimento de unidades de cortes transversais, ao qual corresponde a um maior número de observaçóes. Como resultado, traz-se para a análise uma maior quantidade de informaçóes, variabilidade dos dados, menos colinearidade entre as variáveis, maior grau de liberdade e eficiência dos parâmetros estimados.

De acordo com Balgati (2013), as vantagens dos dados em painel em relação aos dados de corte transversal ou às séries temporais são a forma que os dados se relacionam a indivíduos (empresas, estados, países, etc). Nessas unidades é possível ter uma grande parcela de heterogeneidade e com as técnicas de estimação em painel, é possível levar em conta de forma explícita as variáveis individuais específicas. Além disso, ao combinar séries temporais com dados de corte transversal, os dados em painel permitem dados que são mais informativos, e contém maior grau de liberdade e mais eficiência. Logo, ao estudar de forma repetida um corte transversal de observaçóes, os dados em painel são os mais adequados para o estudo da dinâmica da mudança.

Os dados em painel também permitem estudar modelos comportamentais que são mais complexos. Fenômenos como economias de escala e as mudanças tecnológicas podem ser mais bem acertados por dados em painel do que por corte transversal puro ou de séries temporais puras. Por último, ao tornar disponíveis os dados referentes a várias milhares de unidades, pode-se minimizar o víeis que passaria da agregação de pessoas ou empresas em grandes conjuntos.

Então, considerando que o modelo de dados em painel trabalha com a combinação de série temporal e seção cruzada, tem-se dados de várias unidades medidas ao longo do tempo. Em outras palavras, considera-se um conjunto de dados com $\mathrm{i}=1,2,3, \ldots, \mathrm{N}$ unidades 
e $\mathrm{t}=1,2,3, \ldots, \mathrm{T}$ períodos de tempo, o modelo econométrico geral para a aplicação da técnica de dados em painel se se apresenta-se como:

$$
Y_{i t}=\propto_{i t}+X^{\prime}{ }_{i t} \beta+\varepsilon_{i t}
$$

em que $Y_{i t}$ é a variável dependente do modelo, $\propto_{i t}$ representa o intercepto, $X^{\prime}{ }_{i t}$ denota um vetor de variáveis explicativas do modelo, $\beta$ refere-se à matriz de coeficientes angulares estimados e $\varepsilon_{i t}$ o termo de erro. Logo, segundo Hsiao (2014) citado por Reinaldo (2017), este modelo geral desencadeia dois modelos típicos básicos, quais sejam, modelo de efeitos fixos (EF) e efeitos aleatórios (EA), que são estimados de acordo com as conjecturas que se faz a respeito da possível correlação entre o termo de erro e as variáveis explicativas $X_{i t}$. Isto é: i) Modelo de efeito aleatório quando $\alpha_{i}$ não é correlacionado com Xit; e, ii) Modelo de efeito fixo quando $\alpha_{i}$ é correlacionado com Xit.

Logo, é importante salientar que a decisão quanto ao uso do modelo de efeitos fixos e efeitos aleatórios não é simples. Assim, na comparação entre os modelos pooled, -dados agrupados- efeitos fixos e aleatórios, para identificar qual destes modelos é melhor, precisase fazer os seguintes testes: i) teste de Chow que se baseia em um teste F cuja a hipótese nula é de que o melhor modelo é o restrito (pooled) contra a alternativa de que o melhor modelo é o de EF; ii) teste de Hausman, que considera a estatística de $\chi^{2}$ e a hipótese nula é que o melhor modelo é o de EA contra a hipótese alternativa de que o melhor modelo é o de EF; e, iii) teste do multiplicador de Lagrange de Breusch -Pagan (LM teste), cuja hipótese nula é de que o melhor modelo é o restrito (pooled) contra a alternativa de que o melhor modelo é o de EA.

Além da escolha quanto ao melhor estimador para o modelo de dados em painel, é necessário verificar se os resultados estimados atendem às premissas da ausência de autocorrelação, heterocedasticidade e multicolinearidade, sendo esta última, pouco comum, pela própria estrutura dos dados em painel. No que concerne à identificação da autocorrelação, geralmente aplica-se o teste de autocorrelação serial de Wooldridge cuja hipótese nula é de ausência de autocorrelação. Para testar a presença de heterocedasticidade, utiliza-se o teste de Wald cuja a hipótese nula é de homocedasticidade. Por fim, é necessário verificar se os resíduos da regressão se distribuem de forma normal.

Destaca-se também que, como se trata de informações analisadas ao longo do tempo e por unidades, é necessário avaliá-las por meio de testes formais de raiz unitárias para o caso de dados em painel. Segundo Baltagi (2013) e Wooldridge (2017), são vários os testes de raiz unitária que podem ser aplicados para dados em painel. Assim, no presente estudo aplicou-se, conforme Baltagi (2013) e Wooldridge (2017), os seguintes testes: Levin-LinChu (LLC), Harris-Tzavalis (HT) e Breitung que apresentam hipótese nula de que painéis contém raiz unitária, contra a hipótese alternativa de que painéis são estacionários. Já o teste Im-Pesaran-Shin (IPS) tem hipótese nula de que todos os painéis são estacionários contra a hipótese alternativa de que alguns painéis são estacionários. Por sua vez, o teste de Hadri se baseia na hipótese nula de que todos os painéis são estacionários contra a hipótese alternativa de que alguns painéis contém raiz unitária. Quanto ao teste de Fisher, 
este apresenta hipótese nula de que todos os painéis contém raiz unitária contra a hipótese alternativa de que pelo menos um painel é estacionário.

\subsection{Descrição das Variáveis e fonte de dados}

Nesta subseção, descreveu-se as variáveis que compuseram o modelo econométrico aplicado para mensurar os impactos dos determinantes do acidente de trânsito no Brasil sobre os custos do SUS. Tais informaçóes estão em formato de séries anuais para o período de 2002 a 2012. Assim, tem-se:

a) Custo do Sus (CSUS): refere ao custo do SUS com acidentes de trânsito de modo geral no Brasil. Para calcular o custo do SUS com acidentes de trânsito, foi necessário identificar o número de acidentes por ano em cada rodovia analisada; e, a partir do número de acidentes, foi descontada a colisão frontal e a colisão traseira. Por último foi tomada a média do custo diário que o SUS tinha no ano de 2010 por cada paciente, que foi de $\mathrm{R} \$ 180,65$. Por meio da literatura também foi identificado que, em média, uma pessoa acidentada ficava internada por 6,3 dias, conforme informaçōes de 2010; logo, multiplicou-se esse número de dias pelo custo diário e por último multiplicou-se pelo número de acidentes em cada rodovia por ano, de modo a ter a seguinte equação: CSUS= (número de acidentes - colisão frontal - colisão traseira)* $180,65^{*} 6,3$. Tais dados foram obtidos por meio de pesquisa em relatórios disponibilizados pelo IPEA, site Vias Seguras, Agência Nacional de Transporte Terrestre -ANTT e demais órgãos setoriais. Os dados foram deflacionados para obter o custo diário dos outros anos.

b) Colisão Frontal (CF): é o número de acidentes que ocorreram por colisão frontal (acidentes que ocorrem quando os veículos colidem de frente) nas seis rodovias federais concedidas que foram analisadas.

c) Colisão Traseira (CT): refere-se ao número de acidentes que ocorreram por colisão traseira, também nas seis rodovias federais analisadas.

Destaca-se que as variáveis que se relacionam aos números de acidentes (CF e CT), assim como o investimento foram obtidas nos relatórios anuais da ANTT.

d) Investimento (I): denota o valor dos investimentos realizados nas seis rodovias, no período de 2002 a 2012. Estes dados foram obtidos por meio dos relatórios anuais e demonstraçóes financeiras das empresas que operam nas rodovias federais concedidas.

e) Quilometragem (KM): refere-se ao trecho concedido a cada uma das seis concessionárias que exploram essas rodovias federais analisadas. Os dados podem ser obtidos no site da ANTT.

f) Lei Seca (LS): trata-se de uma variável dummy que busca avaliar se a criação da Lei Seca, que entrou em vigor no ano de 2008, gerou algum o efeito da criação da Lei Seca. Logo, definiu-se o valor (1) para o período pós 2008, e, zero (0) zero para o caso contrário. 


\subsection{Modelo Econométrico proposto}

Para mensurar os impactos de determinantes dos custos do SUS com acidentes de trânsito em rodovias federais brasileiras, utilizaram-se dados de séries de tempo para o período de 2002 a 2012, logo a dimensáo tempo do painel foi de 10 anos $(t=10)$. Quanto às unidades (i) o painel foi composto de informaçóes de seis $(i=6)$ rodovias concedidas na primeira etapa do programa de concessão de rodovias no Brasil, que são: NOVADUTRA (Rio de Janeiro - São Paulo), PONTE (Rio- Niterói), CONCER (Rio de Janeiro - Juiz de Fora), CRT (Rio de Janeiro- Teresópolis - Além Paraíba), CONCEPA (Osório-Porto Alegre), ECOSUL (Pólo de Pelotas). Portanto, tem-se 60 observaçóes que formam um painel balanceado, pois existem o mesmo número de observaçóes para cada dado de corte transversal.

Quanto ao método de estimação, como ressaltado, modelos de dados em painel, geralmente são estimados ou por efeitos fixos (EF) ou efeitos aleatórios (EA). Assim, o modelo que melhor atendeu às características desse estudo foi o modelo de EA e este foi usado para estimar os parâmetros da regressão apresentada na Equação (2).

$$
\text { LOGCSUS }_{i t}=\beta_{0}+\beta_{1} \text { CF }_{i t}+\beta_{2} \text { LOGCT }_{i t}+\beta_{3} L O G I_{i t}+\beta_{4} L O G K M_{i t}+\beta_{5} L S_{i t}+\eta_{i t}
$$

em que a variável dependente do modelo é o LOGCSUS que se refere ao logaritmo do custo do SUS com acidentes de trânsito na rodovia i no Brasil no período t. CF referese ao número de acidentes devido à colisão frontal nas rodovias i e no período t. LOGCT refere-se ao logaritmo do número de acidentes oriundos de colisão traseira, na rodovia i no período t. LOGI denota o logaritmo do valor investido na rodovia pela concessionária i no período t. Já LOGKM refere-se à extensão do trecho cedido para a concessionária i no tempo t. LS indica uma variável dummy para verificar o efeito da criação da Lei Seca em 2008. E, por fim, $\eta_{i t}$ é o termo de erro estocático.

Dado que as variáveis utilizadas na análise englobam valores discrepantes (desde milhóes referentes aos custos do SUS com acidentes, a valores bem menos expressivos, como a extensão da rodovia), optou-se por utilizar um modelo Log-Log, pois este além de permitir suavizar os efeitos de tal discrepância, ainda facilita a interpretação dos dados, visto que para as variáveis que estão em logaritmo a análise pode ser feita em termos percentuais. Ademais, para estimação da Equação (2) e obtenção dos resultados econométricos, foi utilizado o software Estatístico Stata 12.

Por fim, como forma de sintetizar as relaçóes apontadas pela revisão de literatura entre os determinantes e o custo do SUS com acidentes de trânsito, apresentam-se no Quadro 1 os sinais que os parâmetros $\beta^{\prime}$ s devem apresentar. Isto porque, ainda não há uma teoria consolidada que indique a relação exata que se espera obter para tais parâmetros. 
Quadro 1- Relação entre os parâmetros estimados para os determinantes do custo do SUS com acidentes de trânsito no Brasil, considerando o período de 2002 a 2012.

\begin{tabular}{|c|c|l|}
\hline Parâmetros & $\begin{array}{c}\text { Sinal } \\
\text { esperado }\end{array}$ & \multicolumn{1}{|c|}{ Interpretaçáo } \\
\hline $\boldsymbol{\beta 0}$ & + & Custo médio do SUS com acidentes de trânsito. \\
\hline $\boldsymbol{\beta 1}$ & + & $\begin{array}{l}\text { O aumento do número de acidentes por colisão frontal aumenta o } \\
\text { custo médio do SUS. }\end{array}$ \\
\hline $\boldsymbol{\beta 2}$ & + & $\begin{array}{l}\text { Quanto maior o número de acidentes causados por colisão traseira, } \\
\text { maior tende a ser o custo médio do SUS. }\end{array}$ \\
\hline $\boldsymbol{\beta 3}$ & - & $\begin{array}{l}\text { Quanto maior forem os investimentos nas rodovias, menor tende } \\
\text { a ser o número de acidentes e com isso, reduz-se o custo médio do } \\
\text { SUS. }\end{array}$ \\
\hline $\boldsymbol{\beta 4}$ & + & $\begin{array}{l}\text { Quanto maior o trecho nas rodovias, maior tende a ser o número de } \\
\text { acidentes, acarretando num aumento do custo do SUS. }\end{array}$ \\
\hline $\boldsymbol{\beta 5}$ & - & $\begin{array}{l}\text { A implantação da Lei Seca pode ter reduzido o número de acidentes, } \\
\text { e com isso reduzir também o custo médio do SUS. }\end{array}$ \\
\hline
\end{tabular}

Fonte: Elaboração própria.

\section{Resultados e discussáo}

Nesta seção foram expostos e discutidos os resultados econométricos deste artigo. Inicialmente, apresentaram-se os resultados do teste de raiz unitária na Tabela 1.

Tabela 1- Resultado dos testes de Raiz Unitária para as variáveis utilizadas para determinar os efeitos dos determinantes sobre os custos do SUS com acidentes de trânsito no Brasil, considerando as rodovias federais analisadas, 2002 a 2012

\begin{tabular}{lccccc}
\hline TESTE/SÉRIE & LOGCSUS & CF & LOGCT & LOGI & LOGKM \\
\hline LLC $_{\mathrm{t}}$ & $-2,728^{* * *}$ & $-3,592^{* * *}$ & $-2,198^{* *}$ & $-16,854^{* * *}$ & - \\
LLCnct & $5,467^{\mathrm{NS}}$ & $0,391^{\mathrm{NS}}$ & $2,230^{\mathrm{NS}}$ & $2,660^{\mathrm{NS}}$ & - \\
LLCd & $-2,423^{* * *}$ & $-2,507^{* * *}$ & $-1,162^{\mathrm{NS}}$ & $-3,830^{* * *}$ & - \\
HTt & $-0,143^{* * *}$ & $-0,140^{* * *}$ & $-0,305^{* * *}$ & $-0,044^{* * *}$ & $0,000^{* * *}$ \\
HTnct & $1,008^{\mathrm{NS}}$ & $0,955^{\mathrm{NS}}$ & $1,005^{\mathrm{NS}}$ & $1,007^{\mathrm{NS}}$ & $1,000^{\mathrm{NS}}$ \\
HTd & $0,208^{* * *}$ & $0,081^{* * *}$ & $0,013^{* * *}$ & $0,117^{* * *}$ & $0,000^{* * *}$ \\
BREITUNGt & $-0,841^{\mathrm{NS}}$ & $-2,804^{* * *}$ & $-1,454^{*}$ & $-2,377^{* * *}$ & - \\
BREITUNGnct & $4,317^{\mathrm{NS}}$ & $-1,064^{\mathrm{NS}}$ & $1,151^{\mathrm{NS}}$ & $1,280^{\mathrm{NS}}$ & - \\
BREITUNGd & $-1,679^{* *}$ & $-2,530^{* * *}$ & $3,544^{* * *}$ & $-3,191^{* * *}$ & - \\
IPSt & $-2,352^{* * *}$ & $-3,567^{* * *}$ & $-2,985^{* *}$ & $-2,824^{* * *}$ & - \\
IPSd & $-1,557^{*}$ & $-3,037^{* * *}$ & $-2,420^{* * *}$ & $-1,892^{* *}$ & - \\
HADRIt & $0,514^{\mathrm{NS}}$ & $1,242^{\mathrm{NS}}$ & $-0,070^{\mathrm{NS}}$ & $0,972^{\mathrm{NS}}$ & - \\
HADRId & $3,420^{* * *}$ & $2,060^{* *}$ & $1,781^{* *}$ & $1,326^{*}$ & $59,729^{* * *}$
\end{tabular}




\begin{tabular}{lccccc}
\hline TESTE/SÉRIE & LOGCSUS & CF & LOGCT & LOGI & LOGKM \\
\hline HADRIr & $10,415^{* * *}$ & $1,889^{* *}$ & $6,951^{* * *}$ & $7,200^{* * *}$ & $2,738^{\mathrm{NS}}$ \\
FICHERdf & $3,455^{\mathrm{NS}}$ & $0,354^{\mathrm{NS}}$ & $2,328^{\mathrm{NS}}$ & $2,623^{\mathrm{NS}}$ & - \\
FICHERpp & $1,204^{\mathrm{NS}}$ & $-5,098^{* * *}$ & $-0,076^{\mathrm{NS}}$ & $0,694^{\mathrm{NS}}$ & - \\
FICHERdfd & $1,320^{\mathrm{NS}}$ & $0,680^{\mathrm{NS}}$ & $1,530^{\mathrm{NS}}$ & $-0,586^{\mathrm{NS}}$ & - \\
FICHERppd & $-1,93043^{* *}$ & $-5,607^{* * *}$ & $-3,191^{* * *}$ & $-2,892^{* * *}$ & - \\
\hline DECISÃO & $\mathbf{I}(\mathbf{0})$ & $\mathbf{I}(\mathbf{0})$ & $\mathbf{I}(\mathbf{0})$ & $\mathbf{I}(\mathbf{0})$ & $\mathbf{I}(\mathbf{0})$ \\
\hline
\end{tabular}

Fonte: Elaboração própria a partir dos resultados da pesquisa.

Nota 1: $\left(^{* *}\right)$ refere-se a significativo a $1 \%$ de significância estatística; $\left({ }^{* *}\right)$ refere-se a significativo a $5 \%$ de significância estatística; $\left(^{*}\right)$ refere-se a significativo a $10 \%$ de significância estatística; e, (NS) refere-se a não significativo do ponto de vista estatístico. Além disso, o subscrito t refere-se ao modelo com tendência; nct refere-se ao modelo sem constante; $\mathrm{d}$ refere-se ao modelo subtraindo as médias nas cross-sections; $\mathrm{r}$ permite independência entre as cross-sections; DF significa Dickey-Fuller aumentado (ADF); pp significa Phillips-Perron; dfd refere-se ao teste usando o ADF e subtraindo as médias nas cross-sections, e; ppd denota o teste usando a estatística de Phillips-Perron e subtraindo as médias nas cross-sections. Detalhes sobre as especificaçóes de cada teste podem ser encontrados em Baltagi (2013) e Wooldridge (2017).

Nota 2: Para a decisão quanto a presença ou ausência de raiz unitária considerou-se o que a maioria dos testes apontaram para cada variável.

Conforme resultados apresentados na Tabela 1 , observou-se que as séries analisadas foram estacionarias em nível e, portanto, adequadas à aplicação dos estimadores de dados em painel. Assim, o próximo passo da análise consistiu na escolha do melhor modelo para estimação da Equação 2, cujos resultados obtidos para as estimativas de Efeito Aleatório (EA)estão apresentados na Tabela 2.

Tabela 2- Resultados dos coeficientes estimados por EA, considerando o período de 2002 a 2012

\begin{tabular}{llll}
\hline & Coeficiente & erro - padráo & $\mathbf{P}>|\mathbf{z}|$ \\
\hline Constante & 2,6128 & 0,3144 & 0,000 \\
CF & 0,0004 & 0,0124 & 0,745 \\
LOGCT & 0,6113 & 0,0541 & 0,000 \\
LOGI & 0,0469 & 0,0278 & 0,092 \\
LOGKM & 0,6786 & 0,0858 & 0,000 \\
LS & 0,1293 & 0,04584 & 0,005 \\
\hline
\end{tabular}

\begin{tabular}{ll}
\hline \multicolumn{3}{l}{ Teste Wald (teste de significância conjunta dos regressores) $=1.246,21^{* * *}$} \\
\hline \multicolumn{3}{l}{ Teste de autocorrelaçáa (teste $\mathrm{F})=13,68^{\mathrm{NS}} \quad$ Teste de White $=66^{\mathrm{NS}}$} \\
\hline \multicolumn{2}{l}{ Teste de Multicolinearidade (FIV médio) $=2,17 \quad$ teste de normalidade $6,76^{\mathrm{NS}}$} \\
\hline
\end{tabular}

Fonte: Elaboração própria a partir dos resultados da pesquisa.

Nota 1: $\left.{ }^{* * *}\right)$ refere-se a significativo a $1 \%$ de significância estatística; $\left({ }^{* *}\right)$ refere-se a significativo a $5 \%$ de significância estatística; $\left(^{*}\right)$ refere-se a significativo a $10 \%$ de significância estatística; e, (NS) refere-se a não significativo do ponto de vista estatístico. Além disso, as estimativas foram corrigidas para obter erros-padrão robustos. 
De acordo com os resultados apresentados na Tabela 2, observa-se que, de modo geral, os sinais dos coeficientes estimados foram condizente com as discussóes da literatura, à exceção dos obtidos para o investimento e para a colisão frontal $(\mathrm{CF})$, que não foram significativos do ponto de vista estatístico, considerando $5 \%$ de significância estatística. Entretanto, pelo teste Wald, tem-se que, em conjunto, as variáveis são estatisticamente diferentes de zero, ou seja, elas explicam o custo do SUS com acidentes de trânsito em rodovias federais no Brasil, considerando o período de 2002 a 2012. Observou-se também se havia problemas de autocorrelação serial no modelo e o resultado do teste de Wooldridge indicou não significativo, isto é, ausência de autocorrelação. Testou-se também a presença de heterocodasticidade via teste de White e o resultado indicou para a não rejeição da hipótese nula. Além disso, verificou se o modelo apresentava problemas de multicolinearidade por meio da análise do Fator de Inflação da Variância (FIV). Os resultados indicaram um FIV médio inferior a 10, neste caso não há suspeitas de problemas de multicolinearidade.

Quanto às estimativas obtidas para os parâmetros da regressão apresentadas na Tabela 2, nota-se que, em média, o custo do SUS com acidentes de trânsito em rodovias federais no Brasil foi de aproximadamente $\mathrm{R} \$ 410,02$ (antilogaritmo de 2,6128) por acidentado mantendo tudo o mais constante. Com relação aos acidentes oriundos de colisão traseira (CT), observa-se, que um aumento de $1 \%$ no número desses acidentes implica, em média, em aumentar em $0,61 \%$ o custo do SUS, tudo o mais mantido constante.

No que diz respeito à relaçâo entre a extensão da rodovia concedida $(K M)$ e o custo de acidentes de trânsito em rodovias federais no Brasil, observou-se, de acordo com os resultados apresentados na Tabela 2, que um aumento de $1 \%$ na extensão do trecho concedido implica em aumentar, em média, o custo do SUS com acidentes de trânsito em cerca de $0,68 \%$, tudo o mais mantido constante. Assim, dado que, em termos médios, a extensão das rodovias analisadas é de aproximadamente $135 \mathrm{~km}$, isto significa que, ao aumentar o trecho em cerca de um quilometro o custo do SUS aumenta de R $\$ 1.148,15$ para $R \$ 1.156,65$, ou $R \$ 8,50$ por $\mathrm{Km}$, isto porque, rodovias com maior extensão no Brasil, geralmente, são as de maior fluxo de veículos de passeios e de carga, visto que muitas vezes fazem ligaçáo entre os estados, o que pode levar a aumentar os riscos de acidentes por excesso de velocidade, cansaço e desatenção dos motoristas devido ao tempo de viagem e até mesmo, precariedade de alguns trechos, pois no período analisado, muitas concessionárias ainda não tinham realizados os todos os investimentos em melhorias das estradas

Ao analisar a colisão frontal (CF), o valor estimado não foi significativo do ponto de vista estatístico, mesmo que esse foi considerando um dos principais tipos de acidentes que levam a óbito. Isto pode ter ocorrido em função de a CF apresentar menor frequência, média de 28 acidentados contra 417 oriundos de CT. Logo, em termos comparativos, a CF pode não causar tanto impacto nos custos dos SUS, uma vez que geralmente as vítimas morrem o que significa menos tempo de cuidados médico-hospitalares.

Quanto à relação observada entre os efeitos dos investimentos e os custos do SUS com acidentes de trânsito, esta também se apresentou não significativa do ponto de vista estatístico. Isso pode ter ocorrido em função da malha rodoviária brasileira apresentar grande necessidade de investimentos para recuperação e ampliação de suas rodovias, tornando-as mais seguras para a trafegabilidade. Inclusive isto tem sido a justificativa para que o poder 
público, nos últimos anos, tenha buscado parcerias público-privadas via concessões, o que confere ao setor privado o direito de explorar economicamente tal infraestrutura pública em troca de que estas concessionárias garantam a qualidade do serviço prestado, o que infelizmente nem sempre tem ocorrido.

Por fim, também se verificou que a estimativa da relação entre a criação da Lei Seca em 2008 foi significativa do ponto de vista estatístico, porém obteve-se uma relação diretamente proporcional ao custo do SUS, o que contradiz o que se esperava a priori. Tal situação, pode ter ocorrido em função do fato de que a Lei Seca, apesar de criada em 2008, só começou a ser mais efetiva em 2012, com a implantação da tolerância zero e multas para quem fosse pego dirigindo embriagado. Entáo, considerando que o horizonte temporal dessa pesquisa cobre o período de 2002 a 2012, acredita-se que isso pode ter implicado na "descrença" por parte do motorista quanto a real punição até essa data.

\section{Consideraçóes finais}

O presente artigo teve como principal objetivo identificar e mensurar os impactos dos determinantes nos custos do SUS com acidentes de trânsito em seis rodovias federais concedidas na primeira etapa do PER, considerando o período de 2002 a 2012. Para este fim foi necessário revisão de literatura bibliográfica sobre o tema, com vistas a identificar quais seriam esses determinantes e a partir disso estimar, via modelos de dados em painel, os seus efeitos sobre os custos do SUS com acidentes de trânsito em rodovias federais no Brasil.

Os resultados obtidos, de modo geral, estáo em conformidade com o modelo empírico proposto, com exceção dos acidentes por colisão frontal e investimentos nas rodovias analisadas, uma vez que estes determinantes náo se mostraram significativos do ponto de vista estatístico. Observou-se relação positiva e diretamente proporcional entre os acidentes gerados por colisão traseira e o custo do SUS com acidentes de trânsito. Da mesma forma, quanto maior o trecho cedido, maior o custo do SUS com acidentes de trânsito, uma vez que há maior volume de trafego diário nas rodovias. Já, em se tratando da Lei Seca, apesar desta ter se mostrado estatisticamente significativa, observou-se uma relação positiva e diretamente proporcional, sendo que não era o esperado, pois, à medida que se implanta uma lei com o objetivo de diminuir o número de acidentes, ela deveria ter relaçáo negativa com o custo do SUS. Mas, acredita-se que tal relação possa ter ocorrido em função do período analisado, 2002 a 2012, sendo que somente em 2012 a Lei Seca passou a ser mais efetiva dado os ajustes realizados.

Portanto, a partir dos resultados obtidos afirma-se que a hipótese da presente pesquisa não foi refutada, pois os determinantes, colisão traseira e a extensão do trecho cedido, foram significativas para explicarem os custos do SUS associados aos acidentes de trânsito no Brasil.

Em tempo, para a realização desta pesquisa, encontrou-se algumas dificuldades, principalmente no que diz respeito à Lei Seca que passou a ser tratada com maior rigidez somente em 2012, último ano da análise, e isto, pode ter impedido que se capturasse o efeito da imprudência dos motoristas, determinante apontado na revisão de literatura com uma das causas mais frequentes dos acidentes dessa natureza. Portanto sugere-se para futuras 
pesquisas que se estenda o período analisado para anos posteriores a 2012 de tal sorte que se possa testar o efeito da Lei Seca, quando esta passou a ser mais rigorosa.

Além disso, destaca-se também como outra dificuldade quanto à indisponibilidade de alguns dados que seriam necessários para que a análise pudesse englobar o exame das relaçóes entre o custo do SUS e outros determinantes relacionado à imprudência, tal como o excesso de velocidade. Se tais informações tivessem disponíveis, estudos nesta área poderiam servir de base para implementação de açóes por parte do poder público e da sociedade de modo geral, com vistas a chamar a atenção pelo fato de que os acidentes de trânsito impactam de forma direta e indireta a vida de muitas pessoas.

Por fim, cabe dizer que os acidentes de trânsito causam um grande impacto na economia do país, à medida que retira muitas pessoas em idade economicamente ativa da força de trabalho produtiva; e, também gera impacto no orçamento público destinado a área da saúde. Portanto, mesmo que não seja possível calcular os custos de forma exata, sejam eles econômico e, ou social, pois a perda de uma vida é irreparável e imensurável, acredita-se ser necessário analisar as variáveis que impactam diretamente no custo do SUS com acidentes de trânsito, uma vez que os valores aplicados em atendimentos médicohospitalares não são inexpressivos.

\section{Referências}

BALTAGI, B. H. EconometricAnalysisofPanel Data. Editora Wiley; 5a ed. 2013. 373p.

COMISSÃO EUROPÉIA. Mobilidade e Transportes. Disponível em: <https:// ec.europa.eu/transport/road_safety/topics/behaviour/speeding_pt $>$ Acesso em: 10 -082017.

\section{CONFEDERAÇÃO NACIONAL DE TRANSPORTE. Pesquisa CNT de rodovias} 2016: Relatório Gerencial. Brasília, 2016. Disponível em: <http://pesquisarodovias.cnt. org.br/Edicoes>. Acesso em 30-10-2016.

\section{CONFEDERAÇÃO NACIONAL DE TRANSPORTE. Pesquisa CNT de rodovias}

2015: Relatório Gerencial. Brasília, 2015. Disponível em :<http://pesquisarodovias.cnt. org.br/Edicoes $>$.Acesso em 30-10-2016.

EMPRESA BRASIL DE COMUNICAÇÃO S/A - EBC BRASILEIRA. Lei Seca reduziu acidentes, mas é preciso pensar em alternativas ao carro. Disponível em: $<$ http://agenciabrasil.ebc.com.br/geral/noticia/2016-02/lei-seca-reduziu-acidentes-mas-epreciso-pensar-em-alternativas-ao-carro>. Acesso em: 10-08-2017.

FELICISSIMO, A. Economia da Saúde, 2000. Disponível em <https://pt.scribd.com/ document/94605185/Economia-da-Saude-Angelo-Felicissimo >. Acesso em 31-05- 2017.

GUJARATI, D. N.; P, D. C. Econometria Básica-5. McGraw Hill Brasil, 2011. 
INSTITUTO DE PESQUISA ECONÔMICA APLICADA - IPEA. Acidentes de trânsito nas Rodovias Federais Brasileiras - Caracterização, tendências e custos para a sociedade. Brasília, 2015. Disponível em: <http://www.ipea.gov.br/portal/images/stories/ PDFs/relatoriopesquisa/150922_relatorio_acidentes_transito.pdf >. Acesso em 29-102016.

INSTITUTO DE PESQUISA ECONÔMICA APLICADA-IPEA. Estimativa dos Custos dos Acidentes de Trânsito no Brasil com Base na Atualizaçáo Simplificada das Pesquisas Anteriores do Ipea.2016. Disponível em: http:/www.ipea.gov.br/portal/index. php?option=com_content\&view=article\&id=27755. Acesso em 31-07- 2017.

INSTITUTO NACIONAL DE CIÊNCIA E TECNOLOGIA- OBSERVATÓRIO DAS METRÓPOLES. Evoluçáo da Frota de Automóveis de Moto no Brasil 2001-2012- Relatório 2013. Rio de Janeiro, 2013. Disponível em: <http://www. observatoriodasmetropoles.net/download/auto_motos2013.pdf>. Acessoem 11-11- 2016.

LEITE, C. B. Abel-Smith, Brian. Value for money in medicai services. London Heinemann, 1976. p. 173.Rio de Janeiro, 1977. Disponível em: <http://bibliotecadigital. fgv.br/ojs/index.php/rap/article/viewFile/6147/4763>. Acesso em 07-08- 2017.

MAPA DA VIOLÊNCIA. Acidentes de Trânsito e Motocicletas. Rio de Janeiro, 2013. Disponível em: <https://www.mapadaviolencia.org.br/pdf2013/mapa2013_transito.pdf>. Acesso em 20-09-2018

MARÍN, L.; QUEIROZ, M. R. A atualidade dos Acidentes de Trânsito na era da velocidade: Uma visão geral.Cad. Saúde Pública, Rio de Janeiro, 2000. Disponível em: <http://taurus.unicamp.br/bitstream/REPOSIP/32519/1/S0102-311X2000000100002. pdf>. Acesso em 20-09-2018.

MASSAU, G.C; ROSA, R.G. Acidentes de Trânsito e Direito à Saúde: Prevenção de Vidas e Economia Pública. Disponível em: <http://www.revistas.usp.br/rdisan/article/ view/122305/119042>. Acesso em 08-12-2017.

MEDICI, A. C. Kenn.eth Arrow (1921-2017) e a economia da saúde. Disponível em: <https://www.researchgate.net/publication/314278187_Kenneth_Arrow_19212017_e_a_Economia_da_Saude>. Acesso 29-06-2017.

MELAMED, C.; PIOLA, S. F. Políticas Públicas e Financiamento Federal do Sistema Único de Saúde. Brasília: IPEA, 2011.Disponível em <http:/www.ipea.gov.br/portal/ images/stories/PDFs/livros/livro_politpublicas_saude.pdf>. Acesso em 09-05-2017.

NERO, C. R. Del. O que é Economia da Saúde. In:Economia da Saúde: Conceito e Contribuição para a Gestáo de Saúde. $3^{a}$ Edição. Brasília, 2002, pp. 5 - 21. 
ORGANIZAÇÃO DAS NAÇÕES UNIDAS BRASIL- ONUBR.Acidentes no trânsito ainda matam 1,25 milhão por ano, 90\% em países de renda média e baixa, 2015.

Disponível em: <https://nacoesunidas.org/onu-acidentes-no-transito-ainda-matam-125milhao-por-ano-90-em-paises-de-renda-media-e-baixa/>. Acesso em 14-08-2019.

ORGANIZAÇÃO PAN-AMERICANA DA SAÚDE (OPAS). Folha informativa - Acidentes de trânsito. 2019.Disponível em: https:/www.paho.org/bra/index. php?option=com_content $\&$ view=article $\&$ id $=5147$ :acidentes-de-transito-folhainformativa\&Itemid=779> Acesso em 22-02-2019.

ORGANIZAÇÃO PAN-AMERICANA DA SAÚDE. Gestáo da velocidade: um manual de segurança viária para gestores e profissionais da área. Brasília, 2012. Disponível em: <http://apps.who.int/iris/bitstream/10665/43915/4/9789275317099_ por.pdf?ua=1 >. Acesso em: 11-11-2017.

PINSKY, I.; PAVARINO FILHO, R. V. A apologia do consumo de bebidas alcoólicas e da velocidade no trânsito no Brasil: consideraçóes sobre a propaganda de dois problemas de saúde pública. Revista de Psiquiatria do Rio Grande do Sul, v. 29, n. 1, pp. 110-118. 2007.

REINALDO, L. M. Estimação clássica e bayesiana para dados em painel. Dissertação (Mestrado). Programa de Pós-graduação em Estatística do Instituto de Ciências Exatas da Universidade de Brasília. 2017

WOOLDRIDGE, J. M. Introdução À Econometria - Uma Abordagem Moderna EditoraCengageLearning, 6a Ed. 2017.

WORLD HEALTH ORGANIZATION. Global status report on road safety 2018. ISBN 978-92-4-156568-4. 2018. Disponível em: https://www.who.int/violence_injury_ prevention/road_safety_status/2018/en/ Acesso em 23-02-2019. 